Est Ag 48 (2013) 435-450

\title{
Teología de la Tradición en la Dei Verbum Transmisión de la Revelación. ¿Aproximación al luteranismo?
}

SUMARIO. "El Vaticano II supuso la mejor exposición doctrinal, por parte del Magisterio, sobre el concepto teológico de Tradición. Retomando Trento y la gran tradición evangélico-luterana, el Concilio propone una base netamente cristológica de la Tradición, lo cual posibilita superar las teorías de la doble fuente y de la sola Scriptura, proponiendo su naturaleza como organismo vivo/Viva voz del Evangelio, que, a su vez encuentra su raigambre en la persona de Cristo (Evangelio) y un desarrollo-progreso en la Iglesia entera, mediadora de aquel para el mundo. Esta perspectiva cristológico-escatológica, seleccionada deliberadamente por el Concilio (pienso), supone un punto de encuentro entre las distintas confesiones cristianas. Palabras clave: Vaticano II, Magisterio, Tradición, La Escritura sola, Confesiones cristianas.

ABSTRACT. "The Second Vatican Council, by the part of the Magisterium, assumed the best doctrinal exposition about the theological concept of Tradition. Returning to the Trent and to the great Lutheran -Evangelical tradition, the Council proposes a pure Christological base from the Tradition, which makes possible to overcome the theories of double source and of the Only Scripture, proposing it's nature as living organism o Living voice of the Gospel, that, in its turn, finds its root in the Christ's personality (Gospel) and in the progressive development in the whole Church, the mediator for the world. This Christological-Eschatological perspective, deliberately selected by the Council (I think), meant a point of meeting between the different Christian confessions. Key words: Vaticano $I I^{\circ}$, Magisterium, Tradition, Only Scripture, Christian confessions. 
El propósito principal de este artículo es plantear la identidad de la Tradición (surgida de una Naturaleza de la Revelación bien pensada en el Concilio), sin duda alguna, como un punto de encuentro en el camino de la unidad cristiana, que posibilitaría, tal y como propuso el Vaticano II, una reflexión y cambio de praxis en la eclesiología. Para un ajeno en la materia, resultaría paradójico, cuando no perplejo, afirmar que ya Trento y Lutero supusieron una gran aproximación al concepto de Revelación/ Tradición, tal y como lo comprende el último Concilio, y mostraré en este artículo. Por ello, haré referencias al trasfondo teológico del Concilio tridentino, para contrastar, simultáneamente, con el Vaticano II y ofertar un sentido de Revelación/Tradición que posibilite el encuentro ecuménico, ampliando, a su vez, el horizonte eclesiológico.

Previamente a la consideración tridentina sobre si la Tradición contiene o no verdades reveladas, haré una breve referencia a lo que los expertos conciliares refieren sobre la complejidad de la elaboración del documento sobre la Divina Revelación (Dei Verbum). Sin duda, el hecho de que haya sido reconocido como uno de los documentos más elaborados, precisamente en su capítulo II, a la hora de hablar de la Tradición, nos pone ante un problema eclesiológico determinante.

Una vez incoada la complejidad de la Constitución dogmática en su capítulo sobre la Tradición, plantearé, desde Trento y en diálogo con el Vaticano II, cuál es la identidad de la Tradición, su relación con la Escritura, con el concepto-binomio Revelación/Evangelio. Con esto, sin duda, surgirá el problema sobre si la Tradición contiene o no verdades reveladas al margen de la Escritura. El problema de las así llamadas tradiciones no escritas nos llevará al planteamiento del rechazo, por parte del Vaticano II, de 2 principios: el de la Sola Scriptura y el de la teoría de las 2 fuentes de la Revelación.

De este modo, profundizaré en el concepto de Tradición, recogido y elaborado por el Vaticano II, ampliando la reflexión sobre la relación entre Revelación/Evangelio y, Sagrada Escritura y Sagrada Tradición. La consideración conciliar de la Tradición como Evangelio transmitido y "lo que la Iglesia es", sostendrá el progreso de la misma, sin traicionar los datos constitutivos de la Escritura, posibilitando una visión de la Tradición más viva y carismática y no tan institucional e intelectualista.

Llegados a este punto, habremos afirmado distintos principios que nos aproximan a la unidad cristiana: la función criteriológica de la Tradición, en contra de una función de complementariedad de datos y de mera institucionalización; la superación de la teoría de las 2 Fuentes, así 
como de la de Sola Scriptura, sin su referencia histórico-comunitaria; el principio activo, vivo y dinámico que se identifica con toda la Iglesia; el carácter de progreso, provocado por la identidad entre Tradición y lo que la Iglesia es y cree en su vida, doctrina y culto.

Finalmente, al adentrarnos en un contexto más ancho, cuál es la identidad de la Tradición, no sólo como Evangelio, sino como organismo vivo (Tradición Viviente) y como la Viva voz que resuena, nos abrirá una perspectiva teo-cristológica $\mathrm{y}$, por ello, ecuménica que debería suponer un cambio no sólo en el diálogo, sino en la propia estructura eclesiológica.

\section{El problema de la Tradición en la gestación de la Dei Verbum ${ }^{1}$}

Son muchos los estudios que versan sobre la controvertida y discutida Constitución dogmática, hecho por el cual me hace pasar por alto esta cuestión; la sola constatación de la elaboración de 5 esquemas hasta su definitiva promulgación por Pablo VI el 18 de noviembre de 1965, la existencia de una subcomisión dentro de la Comisión doctrinal, los prolongados debates fuera del Aula conciliar, son un caldo de cultivo para comprender la complejidad de fondo ${ }^{2}$.

Sin duda la $D V$ transmite la más rica herencia doctrinal, por parte del Magisterio, acerca de la Divina Revelación y, aún más si cabe, sobre la cuestión de la transmisión de la fe, profundizando, como nunca, sobre el concepto de Tradición (Cap. II, nn. 7-10). El número $8^{3}$ concentrará las afirmaciones más influyentes sobre el sentido de Tradición para la posterioridad, que necesitará de los 3 primeros esquemas debatidos para llegar a su formulación actual ${ }^{4}$.

Ahora bien, en todo el proceso de elaboración de este capítulo, vuelven a entrar en juego los problemas heredados desde Trento acerca de si

${ }^{1}$ Diversos son los estudios que ilustran el complejo proceso de elaboración de la $D V$. Como síntesis bastante clarificadoras $c f$. IzQuiERdo, C., Parádosis. Estudios sobre la Tradición, EUNSA, Pamplona 2006, 80-91; PIÉ-NINOT, S., La Teología fundamental. Dar razón de la esperanza, Secretariado Trinitario, Salamanca $2009^{\mathrm{a}}$, 591-593,624,627 y sobre todo 663 665 .

${ }^{2}$ Cf. IzQuierdo, C., Parádosis, 81. Bett, U., Commento alla Costituzione sulla Divina Revelazione, Torino 1967, como testigo y relator principal de la $D V$.

3 SANZ RuBIALES, La tradición y su crecimiento en el número 8 de Dei Verbum, EUNSA 1985 (tesis). Uno de los trabajos monográficos que tratan sobre el contenido doctrinal del n. 8 de la Constitución.

${ }^{4}$ Cf. íbid. 81-84. 
la Tradición contiene o no verdades reveladas o, de otra manera, cuál es la "entidad" de las tradiciones no escritas. En el n. 8 de la $D V$ se habla de tradición, entendiéndola como la tradición apostólica, llamada oral, para distinguirla de la tradición escrita, es decir, de la tradición viva, pero objetivada en los escritos del Nuevo Testamento.

El concepto de Tradición como organismo vivo y comunitario va a ser primordial para mantener el progreso de la misma, sin caer en la ampliación de las verdades reveladas. Este sentido dinámico y complejo nos acompañará durante toda la reflexión, para responder a las preguntas que surgen de los textos y para concluir una vía de unidad cristiana.

\section{La Tradición, ¿contiene verdades reveladas?}

Este complejo concepto ha hecho que, durante siglos, se mantuviera en la Iglesia una idea confusa de tradición; para llegar a la elaboración final de la $D V$, la Iglesia va a tener que distinguir y precisar los interrogantes que surgen a la hora de hablar de una predicación oral y escrita, como es la cuestión inicial fundamental sobre si la tradición (-es escritas) contiene verdades reveladas o no, que no estén contenidas en la Sagrada Escritura 5 .

Para llegar al Capítulo II de la Constitución dogmática, hay que hacer un recorrido largo para conseguir dar a luz, lo que U. Betti, considera la parte más delicada de la misma. Desde el Concilio de Trento, la consideración más extendida en el mundo católico fue la de aceptar que la Tradición transmitía verdades no contenidas en la Escritura; hasta bien entrado el siglo XX, alrededor de los años 70, hubo que esperar para hacer una correcta hermenéutica teológica del decreto tridentino, así como de un estudio histórico-doctrinal del mismo principio teológico en juego.

Según el texto preparatorio de la $D V$, se ve clara la opción de mantenimiento de la teoría, según la cual, la Tradición contendría y transmitiría verdades no contenidas en la Escritura; de hecho, su propio título, cuyo contenido trataré en el siguiente epígrafe, era claro al respecto: De fontibus revelationis, conteniendo un capítulo expreso De duplice Fonte Revelationis, donde se evidenciaba la doble vertiente de verdades transmitidas (AS I: III, 14-26).

\footnotetext{
5 O'COLLINs, G., Criterios para la interpretación de las tradiciones en: TF. Perspectivas,
} $462-480$. 
Pero entrando ya en el fruto de este estudio tridentino y del argumento histórico doctrinal en sí, la $D V$, basándose en Trento, afirma que las "tradiciones no escritas", traditiones sine scripto (DH 1501), tal como la Escritura, "se han de recibir y respetar con el mismo espíritu de devoción" ( $D V$ 9). Ahora bien, ¿cuál es la aportación de la tradición o tradiciones, entendidas aquí como aquello que no se encuentra en la Escritura?

Veamos lo que el Concilio Vaticano II, después de diversos debates, ofrece como el texto definitivo de $D V$ 9, quedando aprobado así:

"La sagrada Tradición y la Sagrada Escritura están íntimamente unidas y compenetradas. Porque ambas manan del mismo manantial [ex eadem divina scaturigine promanantes], se funden en cierto modo y tienden a un mismo fin.., de donde se sigue que la Iglesia no saca solamente de la Sagrada Escritura su certeza acerca de todas las verdades reveladas" [quo fit ut Ecclesia certitudinem suam de omnibus revelatis non per solam sacram Scripturam hauriat: DV 9].

Dejando aparte la unidad entre Escritura y Tradición, así como la descentralización de sí mismas hacia un único manantial, cuestión que desarrollaré en el apartado siguiente, en este número, junto con su anterior, el 8, nos dan la clave para comprender la función de la Tradición dentro de la transmisión de la Revelación o Evangelio, tal y como el Concilio propone, negando la ampliación de verdades no contenidas en la Escritura.

En el número 8, encontramos la afirmación central y clara de cuál sería una de las 2 funciones: "la misma Tradición da a conocer a la Iglesia el canon de los Libros sagrados y hace que los comprenda cada vez mejor y los mantenga siempre activos".

Ahora bien, si unimos la última parte de la afirmación, " comprenda cada vez mejor", junto con la no tan clara propuesta del final del número 9: "de donde se sigue que la Iglesia no saca solamente de la Sagrada Escritura su certeza acerca de todas las verdades reveladas", extraemos la segunda función, cual es la interpretación y actualización de la Escritura, expresión también presente en $D V 12$. Así pues, tenemos 3 textos de la Constitución dogmática, 8,9 y 12 , que hacen poder concluir que la segunda función de la Tradición' en la transmisión de la Revelación es la criteriológica-epistemológica, al no sacar únicamente de la Escritura toda la certeza de lo revelado.

Por consiguiente, con la frase más laboriosa del documento, podemos concluir que los aspectos propios de la tradición en aplicación de lo afirmado, son el conocimiento del canon $(D V 8)$ y la interpretación y actualización de la Escritura ( $D V 12)$. 
De este modo, el Concilio parece optar por una vía de integración hacia el principio de la Sola Scriptura, donde la función criteriológica de la Tradición, no iría en contra de la idea de datos constitutivos de la Escritura. No obstante, este texto y el resto del espíritu conciliar, parece alejarse de la preocupación del tema de la suficiencia material o no de la Escritura y subrayar más esa rica interacción entre los 2 modos privilegiados de transmisión (o testigos) de la revelación, donde el uno sin el otro, serían insuficientes para recibir y continuar el flujo de la Revelación de Dios $^{6}$. Tal es así, que el Concilio evitará tratar la expresión o concepto general de suficiencia o insuficiencia aplicados a uno $\mathrm{u}$ otro principio.

Lo que nos interesa para nuestra reflexión, por tanto, es que, según estas primeras aportaciones conciliares de $D V 8,9$ y 12, donde se constata la función criteriológica y epistemológico-dogmática de la Tradición (estableciendo el canon e interpretando la Escritura), nos abre también un horizonte de aproximación al mundo protestante, pudiendo preservar el principio de la Sola Scriptura ${ }^{7}$, con ciertos matices, como veremos a continuación.

\section{Dei Verbum: superación de la teoría de las 2 Fuentes y de la Sola Scriptura}

Este epígrafe nos puede llevar a una contradicción respecto al reconocimiento de la Sola Scriptura, a la que apenas nos hemos referido. Ciertamente, el interés es muy otro como presentaré a continuación. Partamos ahora de Trento para entender mejor el concepto de tradición y el sentido que tienen las tradiciones no escritas respecto de los datos constitutivos, cuestión sobre la que el Vaticano II, por otra parte, no se pronunciará, como ya queda referido. Una equivocada comprensión de Trento, junto a la cuestión mal interpretada/transmitida sobre la teoría de las 2 fuentes, hará que, durante siglos, el concepto de tradición, haya sido malentendido.

En Trento, las tradiciones "no escritas", a partir de la polémica protestante de la Sola Scriptura, tienen la clave de su interpretación en este texto:

6 Beumer, J., La tradition orale, Paris 1967, 225-234, donde se reseña la pérdida de importancia y peso respecto al tema de la suficiencia o no de la Escritura según el espíritu conciliar.

7 Cf. PIÉ-Ninot, S., La Teología, 603-604. 
- Dz: "El sacrosanto, ecuménico y universal Concilio de Trento, legítimamente reunido en el Espíritu Santo, bajo la presidencia de los tres mismos Legados de la Sede Apostólica, poniéndose perpetuamente ante sus ojos que, quitados los errores, se conserve en la Iglesia la pureza misma del Evangelio que, prometido antes por obra de los profetas en las Escrituras Santas, promulgó primero por su propia boca Nuestro Señor Jesucristo, Hijo de Dios y mandó luego que fuera predicado por ministerio de sus Apóstoles a toda criatura (Mt 28,19 s; Mc 16,15) como fuente de toda saludable verdad y de toda disciplina de costumbres; y viendo perfectamente que esta verdad y disciplina se contiene en los libros escritos y las tradiciones no escritas que, transmitidas como de mano en mano, han llegado hasta nosotros desde los apóstoles, quienes las recibieron o bien de labios del mismo Cristo, o bien por inspiración del Espíritu Santo

- perspiciensque, hanc veritatem et disciplinam contineri in libris scriptis et sine scripto traditionibus

- $\quad$ partim... partim (sustituyó a la conjunción copulativa et)

A partir de este texto crucial, hemos de entender la expresión Evangelium (uso sincrónico del término, junto a su significado respecto del luteranismo) que es término típico también de Lutero y equivalente a lo que a partir de la Ilustración se llamará Revelación 8 .

Por tanto, la transmisión de verdades reveladas por la Tradición cae por tierra, al eliminar la idea de las 2 fuentes de la Revelación, desvaneciéndose por una recta comprensión de Trento, ya que este "Evangelio" es "fuente" (este uso, recuperado por el Vaticano II, obedece a su sentido patrístico como las aguas que surgen del seno de Jesús); por tanto el Evangelio debe ser entendido como fuente de "fe y costumbres o principios morales", identificado con la persona de Jesucristo y no con los escritos del N.T.

Pero además, este Evangelio (la persona de Jesucristo) se dice que se contiene en los libros escritos y tradiciones no escritas, uniéndose ambos

8 Cf. Sesboüe, B., op. cit., 110-112: en el decreto Sacrosancta (sesión 4 de Trento, donde sólo hay 1 canon) se pone de relieve la unicidad del Evangelio; se habla de los 2 lugares de testimonio y transmisión de este único Evangelio; se recibe a los 2, concediéndoles el mismo valor. Evangelio es entendido como Revelación, que se contradistingue de Escritura y evangelios escritos. Trento trata de la teología patrística, en la que Evangelio se identifica con la persona y acontecimiento de Jesucristo (Orígenes y Rom 2, 16, tan comentado por Lutero: Comentario a san Juan I, IV, 26: SC 120, 73). 
sintagmas por la sencilla cópula "y" (et), "los libros sagrados y las tradiciones no escritas", eliminando el uso anterior del partim... partim, aunque su intención fuera completamente otra.. Por los intereses, derivados de las controversias con los protestantes, la interpretación posterior más común, atendió a este texto y lo usó para hablar no de "una", sino de "dos fuentes": la Escritura y la Tradición. Pero claramente una hermenéutica seria sobre las Actas conciliares no conduce a esta conclusión. Este trabajo contundente lo han mostrado teólogos de relevancia sobre el análisis de Trento 9 .

Aún más, tal y como he aludido en el párrafo anterior, si atendemos al estudio del decreto Sacrosancta, donde encontramos estas expresiones, veremos cómo el uso de partim... partim, usado en la redacción previa al uso de et, equivalía a "tanto... como" y no a la división del contenido de la Revelación en distintas partes ${ }^{10}$.

La $D V 9$ recogerá estos principios fundamentales de Trento, mostrando la unidad de lo transmitido en el Evangelio de Cristo y ligando las 2 transmisiones en él mismo y tendiendo al mismo fin. Con ello, el Concilio afirma:

1. La Escritura y Tradición brotan del mismo manantial. Con esta expresión se evita hablar de la palabra fuente. Por desgracia, hasta cierto punto, las distintas lenguas tradujeron la expresión "scaturigo" por fuente, sin recoger lo que el texto conciliar pretendía, que era, precisamente, no caer en las reminiscencias de hablar de las 2 fuentes. Preservando la recta intención del Concilio, Escritura y Tradición, brotan del mismo manantial, Cristo, por lo que ninguna de ellas es fuente, sino medio de la Revelación. Se refrenda aún más, con la expresión "único depósito sagrado de la Palabra de Dios" ( $D V 10)$, evitando hablar tanto de las 2 fuentes como de su autonomía.

2. Pero aquí encontramos una línea de conciliación cristiana (es decir, ecuménica), retomando la reflexión del punto precedente. Es cierto que la afirmación de una función criteriológica de la Tradición nos aproxima al protestantismo, pero aquí vamos más allá. Con dicha

\footnotetext{
9 Según Beumer, no se trata de algo doctrinal, sino de una precisión lingüística que pretende evitar equívocos. Lo fundamental será mostrar la unidad del Evangelio, transmitido en un doble canal, pero ante la polémica anti-protestante y fundamentálmente a través de la catequesis, se mantuvo la doble fuente, negando la suficiencia material de la Escritura.

10 Cf. GeIselmann, J.R., Sagrada Escritura y Tradición, Barcelona 1968, 123.
} 
consideración, a partir de $D V 9$, eliminamos la teoría de la doble fuente, pues Escritura y Tradición brotan del mismo manantial que es el Evangelio-Cristo (escapando también de concepciones intelectualistas, gnósticas, instructivistas de la Revelación), pero también erradica la teoría de la Sola Scriptura en cuanto entendida sin su dimensión histórica y comunitaria, sin su carácter de progreso y comunión ${ }^{11}$.

Es más, cualquier historiador de la Iglesia serio o un buen conocedor de la teología de Lutero, será incapaz de sostener que éste no reconocía el necesario progreso de la Escritura, contando también con su dimensión comunitaria y con un referente de continuidad, pero que criticaba la confusión de este progreso con la superioridad respecto del Evangelio. Será este el punto de confusión que, durante siglos, equivocará a la Iglesia de Cristo. El mismo Lutero, "no ponía el dogma en cuestión en el sentido de una afirmación de fe que gozase autoridad". De hecho, permaneció fiel a los sínodos de la iglesia antigua, ya que los juzgaba conformes con el Evangelio ${ }^{12}$.

Por tanto, queda afirmada la complementariedad entre Trento y Vaticano II, así como la superación de la Teoría de la doble fuente de la Revelación, así como la de la Sola Scriptura, entendida como no necesitada de criteriología interpretativa y su referencia histórico-comunitaria.

\section{Relación entre la Revelación Divina y la Sagrada Escritura y Tradición}

\subsection{Evangelio transmitido; lo que la Iglesia es}

Hasta el momento hemos visto que, desde Trento hasta el Vaticano II, hay una orientación doctrinal para comprender a la Escritura y la Tradición como un rico dinamismo de transmisión de la Revelación de Dios, con una necesaria complementariedad, por lo que considerarlas de manera aislada o bien excluyentes, no tendría sentido.

11 De hecho, la teología protestante se manifiesta disponible a restaurar la tradición como lugar de mediación de la fe individual en su dimensión histórica y comunitaria: $c f$. WAGNER, H., "Wort Gottes: IV. Kirchen del Reformation", Lthk (2001) 1302s. y BEINTKER, "Tradition. VI. Dogmatisch": TRE 33 (2002) 718-725.

12 SesboüÉ, B., Theobald, C., La Palabra de la Salvación, Secretariado Trinitario, Salamanca 1997, 109. 
Pero surge otra problemática, sobre el valor de las tradiciones no escritas y la relación entre Sagrada Escritura y Tradición, que estuvo presente en toda la redacción de la Constitución. Está claro, según el Vaticano II, el necesario vínculo entre ambas, pero, ¿dónde está lo constitutivo? ¿La Tradición sería, por tanto, sólo algo aclaratorio? ¿Pero, hasta que la Escritura aparece, qué es lo constitutivo? Todo esto, nos lleva a una cuestión más amplia: la relación de la Revelación divina con la Escritura y la Tradición, problemática que abrirá sus pulmones gracias al más amplio sentido recogido en los conceptos: «Evangelio Transmitido» $\mathrm{y}$ «lo que la Iglesia es».

En efecto, el Evangelio encierra todo el mensaje y la realidad cristiana, independientemente de su modo de transmisión, porque enlaza directamente con Cristo, revelador y al mismo tiempo Revelación de Dios, como quedaba recogido en el número 4 de la misma Constitución. De modo que, el Concilio evitará hablar de la controversia sobre la llamada tradición constitutiva, para tratar sobre la relación entre Escritura y Tradición en este marco más amplio sobre el Evangelio transmitido. Es Dios mismo, de quien proceden tanto la Escritura como la Tradición, las cuales se han de recibir y venerar ambas con un mismo espíritu de piedad ( $D V 9)$. De esta forma, las relaciones entre Escritura y Tradición dejan de ser un problema que hay que resolver para hacerse una idea cabal de la naturaleza de la revelación.

Para superar la dialéctica, al parecer irresoluble entre Escritura y Tradición, además de hablar del Evangelio transmitido, ayudó identificar el dinamismo de la transmisión con la Iglesia misma.

La revelación la recibe la Iglesia de Cristo mismo mediante los Apóstoles, y su misión esencial es, precisamente, la transmisión de la revelación. Ahora bien, en este punto es necesario aclarar el modo como la Iglesia se relaciona con la tradición. El Concilio, en primer lugar, superará la visión intelectualista y extrinsecista, yendo más allá, no considerando la Tradición como realidad que pertenece a la Iglesia y sobre la que la Iglesia domina (hecho derivado de la comprensión de la naturaleza de la Revelación).

Como queda apuntado, el hecho de proponer una identidad/naturaleza de la Revelación de Dios, va a dinamizar una comprensión de la Tradición y de la Iglesia completamente diverso.

En un sentido, la realidad de la Tradición se identifica con la realidad misma de la Iglesia, que se entrega a todas las generaciones; precisamente de ahí arranca el doble significado -activo y pasivo- de la Tradición, al que se refieren algunos Padres conciliares. En efecto, la Iglesia es, al mismo tiempo, transmisora y contenido de la tradición; o expresado con otras palabras, la Tradición existe en la Iglesia, y la Iglesia se entrega en la Tradición. 
Así pues, la superación de un concepto excesivamente intelectual de la Revelación, posibilita también, no identificar a la Tradición como algo cosificado y objetivado que la Iglesia posee y transmite. De este modo, recogiendo la herencia, sobre todo de la Escuela de Tubinga ${ }^{13}$, la Tradición es vista tanto en relación con el Evangelio (su origen dinámico), como con la Iglesia (su mediación, dinámica también), por lo que permite ampliar el marco estrecho de la Tradición supeditada a los datos constitutivos.

Por consiguiente, esta superación intelectualista de la Revelación/ Tradición, arraigada en la visión como Evangelio transmitido y la transmisión de lo que la Iglesia es y cree, nos lleva a acentuar el sentido activo de la tradición. Por tanto, no se trata, simplemente de la transmisión del mensaje (traditum, contenido), sino del acto de entrega de toda la realidad que procede de Cristo $^{14}$. En consecuencia, recibir la tradición implica en los destinatarios un abrirse a esa realidad dejándose afectar por ella en lo más profundo del propio ser, y un incorporarse a ella. Por tanto, la Tradición se presenta con un marcado carácter vital, necesariamente vinculada a la Escritura. Sin duda, un punto sobre el que no nos detendremos, pero que resultaría inocente no tenerlo en cuenta, es el de abandonar este principio de Tradición a las manos de un subjetivismo atroz. Está clara la necesaria referencia a una delimitación objetiva que impida que la tradición se disuelva en pura historia ${ }^{15}$.

La relación entre Revelación y Tradición-Escritura supera, con creces, el mero hecho de transmisión de verdades y de conservación de algo externo a la misma identidad de la Tradición/Iglesia.

\subsection{La Tradición progresa en la Iglesia}

Ahora bien, de esta noción de tradición como organismo vivo, surge el interrogante de cómo puede progresar, qué implicaciones tiene esa transmisión viva, sin caer en un subjetivismo disolvente ni en un intelectualismo inerme.

13 Cf. IzQuierdo, C., Parádosis, 86-91.

14 Cf. íbid. 199.

15 Cf. íbid. 69-76. "Blondel ha contribuido notablemente a la comprensión de la Tradición como un conocimiento de comunión en el que el conocimiento histórico, la reflexión teológica y la praxis cristiana se comunican y se relacionan entre sí sobre el fundamento de su origen común, sin perder por ello su identidad propia". 
Podríamos distinguir 2 posturas mayoritarias: unos, se apuntarían a un progreso sin raíces (nihilismo); otros se aferrarían a una tradición cosificada y sin dinamismo interno. Frente a ambos, la enseñanza del Concilio es clarificadora. Como queda dicho, el Concilio renunció a manifestarse sobre la cuestión de los datos constitutivos, pero sí insistió mucho en el carácter real, y no sólo verbal, de la Tradición.

Al identificar a la Tradición con la entera realidad del Evangelio (la persona de Cristo), como su origen, y con lo que la Iglesia es, como su mediación y desarrollo, tenemos que admitir que la Tradición tiene lugar entre 2 extremos que, precisamente, posibilitan su progreso: el tiempo de los Apóstoles, por un lado, y el cumplimiento de la Revelación de Dios a través de su Iglesia, por otro.

Según esta perspectiva, no podemos entender el dinamismo de la Tradición, sino es desde la dimensión escatológica, en la que se halla, de modo que nunca en este mundo, encontraremos una formulación o vivencia, absolutamente adecuada o definitiva de su realidad ${ }^{16}$.

Según esto, la Tradición progresa, ciertamente, pero también conviene puntualizar que lo hace en modo de desarrollo. Esto conviene matizarlo, para erradicar las controversias surgidas, en torno a la concepción de progreso según evolución, por lo que se admitiría un progreso con añadidos sustanciales al origen; sin embargo, entenderlo según el modo de desarrollo, implica no suponer un aumento sustancial del origen del que parte, porque lo que hace es descubrir la novedad, de otra manera, de lo que ya estaba presente desde el principio ${ }^{17}$. Esta manera de entender el progreso de la Tradición, sin duda, sería otra puerta abierta para la comunión en Cristo, para quienes pueden ver un añadido sustancial en la hermenéutica o teológica.

\section{Conceptos teológicos de la Tradición en el Vaticano II. ¿Aproximaciones luteranas? Aproximaciones cristocéntricas}

Habiendo entendido la función criteriológica de la Tradición, su identidad con Evangelio transmitido y aceptado su progreso, volvamos a los números 8 y 9, para completar la naturaleza de la Tradición y su fundamento más teológico y cristológico, lo cual nos permitirá, no sólo comprenderla mejor, sino encontrarnos más cerca de la unidad cristiana.

El epígrafe final de esta reflexión, pretende retomar los principales conceptos ya surgidos (Evangelio transmitido, lo que la Iglesia es y cree),

16 Cf. ibid. 89,198.

17 Cf. íbid. 88-91. 
para conjugarlos con otros 2 aludidos (Tradición viviente y Viva Voz del Evangelio), para concluir que, tanto Trento como el Vaticano II, no es que supusieran una aproximación a Lutero, sino que tanto la redacción tridentina como la vaticana, ofrecen una raigambre cristológica, al igual que la luterana, que es la que permite hablar de un camino hacia la unidad.

Partimos de nuevo del renovado uso de la palabra "Evangelio" en el Vaticano II, que a su vez se refiere a Trento (DH 1501). Este fue el concepto preferido a la hora de referirse a la Revelación (palabra no común en aquel momento), así como muestra su gran fuerza evocativa en los ambientes 'evangélico'-luteranos.

Pero el Vaticano II va más allá de esta conceptualización, para hablar de Tradición Viviente (ya hemos acentuado el carácter vivo y dinámico) y de Viva Voz del Evangelio ( $D V 8$ ). Esta comprensión tiene, sin duda, una herencia directa con la Escuela de Tubinga, concretamente en la figura de Möhler18.

18 Cf. íbid. 50-55: "En la tradición -escribe-se nos hacen presentes los creyentes de todos los tiempos, se nos aparecen como miembros integrantes de un todo, nos instruyen, nos castigan y corrigen...".

"Otro punto de la crítica móhleriana al principio de sola Scriptura también es moderno porque se refiere a la necesidad de la intersubjetividad en el conocimiento. La sola Escritura lleva al individualismo, y a partir de éste no se puede superar la duda de lo que no puede ser mas que opinión. El texto de la Simbolica en el que esta idea aparece es célebre: «Sin Tradición, no hay doctrina de la Iglesia, ni Iglesia siquiera, sino solo cristianos particulares; no hay certeza ni seguridad, sino solo duda y probabilidad»".

"Pero el espíritu que anima a la Iglesia no nace de su propia inmanencia, sino que es el Espíritu Santo concedido en Pentecostés. Con ello, Móhler apunta a la dimensión pneumatológica de la tradición que tan fecunda sería en la teología en torno al Vaticano II'. La Tradicion no cayó del cielo como un instrumento para ver correctamente lo que Dios dice en la Escritura, sino que se ha constituido en la historia a partir de la conciencia misma de Jesús entregada a los Apóstoles: «Si el cristianismo vivió en el corazón de nuestro Señor y en el de sus apóstoles, llenos del Espíritu Santo, antes de que se hiciera concepto, discurso y letra, nosotros tendremos que afirmar que antes que la letra fue el espíritu".

"La Tradición constituye el presupuesto necesario para la lectura de la Escritura en la Iglesia. Pero ella misma, la Tradición, depende también de presupuestos. La conclusión de Möhler -el espíritu antes que la letra- admite varias interpretaciones, que conviene aclarar antes de seguir adelante".

"El contexto histórico en que vivió Möhler valoraba especialmente lo interior, el espíritu y no sólo el espíritu individual sino también el colectivo. Así se entiende la importancia del carácter vivo que nuestro autor atribuye a la tradición. Espíritu, conciencia, vida... son los términos preferidos para describir la tradición. Siendo todos ellos validos, no bastarían por sí solos para dar una imagen completa de la tradición, ya que ésta es también -y esencialmente- «letra», contenido, fórmula autorizada, magisterio. Möhler tiene una conciencia plenamente eclesial, independientemente de algunas fórmulas que eventualmente merezcan alguna precisión. 
La Tradición Viviente (la Iglesia entera) es quien interpreta la Escritura, por lo que podríamos expresar, aún con algún matiz más interesante, el principio católico de Tradición, que sería la Escritura en la Iglesia $^{19}$, teniendo en cuenta lo propuesto por $D V$ 9: "la tradición transmite íntegramente la Palabra de Dios confiada a los Apóstoles y a sus sucesores para que iluminados por el Espíritu de la verdad...la conserven fielmente, la expongan y la difundan; por eso la Iglesia no saca la certeza sobre todas las verdades reveladas de la sola Escritura". Por eso, "la Iglesia (en cuanto Tradición Viviente) en su doctrina, en su vida y en su culto perpetúa y transmite a todas las generaciones todo lo que ella es y todo lo que cree...".

Estas tres dimensiones "vivientes" manifiestan y perpetúan cómo "Dios que habló en el pasado, habla sin interrupción con la esposa de su Hijo predilecto y el Espíritu Santo por medio del cual la voz viva del Evangelio (vox viva Evangelii: expresión luterana propuesta por Y. Congar) resuena en la Iglesia y a través de ella en el mundo" (DV 8) ${ }^{20}$. De este modo, la Iglesia, en cuanto identificada con la Tradición, mediadora y responsable de la transmisión de la entera realidad cristiana, es, a su vez, mediación del Evangelio en el mundo.

Bella imagen de la Iglesia/Tradición, que recogerá la LG. A una concepción de Revelación, le corresponde una eclesiología. Por una parte, entendemos cómo Tradición Viviente e Iglesia se identifican, pero, por otra y en consecuencia, el dinamismo vivo de la Iglesia se amplía hacia una eclesiología activa de comunión, donde el Magisterio se halla al servicio de la palabra de Dios, pero también al del entero Pueblo de Dios. Resonancias claras en la complementariedad entre LG 12 y 25 , donde el

La referencia preferente al Espíritu y a la actividad del sujeto que aparece en estas palabras ha de ser entendida de acuerdo con el mismo contexto polémico con la teología protestante. Ante la caricatura de la tradición como algo simplemente jurídico que en realidad obligaba a cerrar los ojos ante la palabra viva de la Escritura, Möhler acentúa el aspecto de espíritu y vida que tiene la Tradición.

Enlazando con el texto citado anteriormente encontramos en la Simbolica una afirmación explícita del contenido: «La Tradición es el peculiar sentido cristiano que existe en la Iglesia y se propaga por la educación en la Iglesia; sentido, sin embargo, que no puede pensarse sin su fondo o contenido, sino que se forma más bien por su fondo y en su fondo, de suerte que puede ser llamado un sentido pleno. La Tradición es la palabra de Dios perpetuamente viva en el corazón de los creyentes.

19 Cf. PiÉ-Ninot, S., La Teología, 624-627.

20 Cf. PIÉ-NInOt, S., Un motivo "luterano"nella DV 8. la Viva Vox Evangelii, en: APARicio, C., Dotolo, C., Pasquale, G., Sapere teologico e unità della fede. Studi in onore del Prof. Jared Wicks, Roma 2004, 208-210. 
Magisterio no puede sino entenderse dentro del dinamismo general de la Tradición, teniendo en cuenta la palabra de Dios y las múltiples manifestaciones del Pueblo de Dios, del que es parte y expresión tan sólo con una función, sin rechazar su relevancia, dentro del gran complejo vivo de la Tradición.

Por último, y brevemente, quisiera destacar, cómo esta aproximación cristocéntrica, pienso que se deba a una deliberada intención de la búsqueda de comunión en Cristo con nuestros hermanos cristianos. El paralelismo conceptual entre Lutero y la formulación de Trento y Vaticano II, pero en nuestra sincronía actual, muestra la deliberada acentuación en DV 8, a propuesta de Congar (Möhler), seleccionando expresiones de una obra luterana; este paralelismo tan claro, y pienso intencionado, no puede ser sino un signo de comunión en Cristo. Hasta la fecha, este "hallazgo inédito" se lo debemos al prof. Pié-Ninot en una referencia en 1999 y más desarrollado en una ponencia en torno a la figura de Wicks el año $2004^{21}$.

Pero Evangelio no significa otra cosa que la proclamación y el clamor de la gracia y misericordia de Dios, ganada y conseguida por la muerte de nuestro Señor Jesucristo y no es propiamente lo que está en los libros y se pone por escrito, sino más bien una predicación oral y una palabra viva, y una voz que resuena en todo el mundo y que se la vocifera patentemente de forma que se la oiga por todas partes (WA 12259,8-12) Doctor Martin Luthers Werke. Kritische Gesammtausgabe, (WA), 61 voll., 1883-1983. Edición de Weimer.
De esta forma, Dios, que habló en otro tiempo, habla sin intermisión con la Esposa de su amado Hijo; y el Espíritu Santo, por quien la viva voz del Evangelio resuena en la Iglesia, y por ella en el mundo, va introduciendo a los creyentes en la verdad entera, y hace que la palabra de Cristo habite en ellos abundantemente $(D V 8 \mathrm{c})$.

21 Cf. Pié-Ninot, S., Un motivo.

También merece la pena revisar el libro de Sesboüé, donde explica el desarrollo del principio sobre la Escritura en el evento de la doble Reforma; allí veríamos cómo la teología de fondo es bastante próxima: $C f$. SESBOÜE, B., op. cit., 119-117. 
De este modo, el cristianismo es propuesto no propiamente como una comunidad o religión del libro, sino una comunidad de religión del Evangelio, donde es el mismo Cristo quien es anunciado y celebrado a través de los tiempos, por toda la Iglesia. Este puede ser el punto de unidad entre los diversos cristianos, comprendiendo Escritura y Tradición con un arraigo netamente cristocéntrico. La comunidad de creyentes en Cristo, manifestación de la Revelación/Tradición tiene el deber de que Cristo resuene como voz viva en la Iglesia y por medio de esta, en el mundo. La Iglesia es considerada así como sujeto creyente, la Iglesia de la vox viva Evangelii que mira hacia el horizonte escatológico, donde tendrá su realización/comunión definitiva en el final de los tiempos. 